\title{
Field investigation on the infiltrations of reservoir and sea waters in summer dry season in Lebna watershed, Tunisia
}

\author{
A. Kawachi ${ }^{1}$, M. Tsujimura ${ }^{2}$, M. Takahashi ${ }^{2}$, A. Chekirbana ${ }^{2}$, \\ J. Tarhouni ${ }^{3}$, W. Yamada ${ }^{2}$ \& H. Isoda ${ }^{1,2}$ \\ ${ }^{1}$ Alliance for Research on North Africa, University of Tsukuba, Japan \\ ${ }^{2}$ Graduate School of Life and Environmental Sciences, \\ University of Tsukuba, Japan \\ ${ }^{3}$ National Agronomic Institute of Tunisia, Tunisia
}

\begin{abstract}
A groundwater table survey, and chemical analyses of surface water and groundwater were performed in the coastal, shallow, aquifer of Lebna watershed (Cap Bon peninsula, Tunisia) in order to examine the infiltration effects of reservoir and sea waters. This was undertaken because, in this region, there is the Lebna dam reservoir, constructed to accelerate recharge of surface water and improve groundwater level depression, and seawater intrusion of the shallow aquifer, the effect has not been evaluated quantitatively yet. Measuring the groundwater level and water quality and collecting the water samples for analysis of inorganic solute ions were carried out in July 2010at 63 locations, including private wells, the river and reservoir. According to the contour map of the groundwater table, the groundwater flow from the reservoir was found in the downstream area of the reservoir only. On the other hand, the groundwater level around the estuary of the Lebna River was lower than the sea, thus seawater intrusion seemed to occur there. In addition, from the results of the chemical analyses, the spatial distribution of chloride ion concentration, which is used as a tracer, also showed that the reservoir water infiltrates the downstream area. Therefore, the effect of the reservoir water infiltration in the summer dry season was limited to the small area.
\end{abstract}

Keywords: dam reservoir, coastal aquifer, seawater intrusion, infiltration, groundwater contour map, chloride. 


\section{Introduction}

Groundwater is an accessible water resource, so it is exploited easily for agricultural, industrial and domestic uses. However, groundwater degradation has become a common environmental problem in the worlds the water consumption increases due to population growth. The water resource heavily depends on groundwater in the dry areas: semi-arid and arid areas. In addition, the coastal regions where the population is concentrated possess the risk of seawater intrusion due to groundwater level decline.

Tunisia is one of the North African countries along the Mediterranean Sea and has various climatic zones: humid, sub-humid, semi-arid and arid. There are also many coastal aquifers in this country. Seawater intrusion has been already reported to occur due to intensive groundwater exploitation for irrigated agriculture $[1,2]$. In order to improve the groundwater quality, surface water stored in the reservoirs of the northern mountain area (the humid and sub-humid regions) is transferred to the coastal urban and farming areas through pipe lines and canals. In addition, many reservoirs have been constructed in the semi-arid regions not only to store the surface water, but also to recharge the groundwater from the reservoirs.

In Korba aquifer which is a coastal aquifer located in the east of Cap Bon peninsula, several dam reservoirs have also been constructed along the rivers to improve the water quality. However, the reservoir effects to groundwater conditions have not been investigated yet. In addition, it is considered that the dam constructions cause the reduction of freshwater inflow to the downstream river, and as a result the infiltration inflow of freshwater from the river into the aquifer also is reduced. It affects the quality and quantity of the groundwater, however, it has also not been investigated.

Therefore, in this paper, the present conditions of the groundwater of a coastal aquifer was investigated by a field survey and analysis of inorganic solute ion concentrations in the ground and surface waters in order to examine the infiltration effects of the reservoir and sea waters.

\section{Study area}

The study area is the downstream area of the Lebna dam reservoir located in the east side of Cap Bon peninsula, Tunisia (figure 1). The area of Lebna watershed is $230 \mathrm{~km}^{2}$. The altitude of the main study area ranges from 0 meters at the coast to 50 meters at the peak. The geology of the downstream area includes Pliocene sand, crust and calcareous and alluvial dune. A large shallow aquifer called 'Korba aquifer' exists in the area. The geology of the upper area is Miocene sandstone and marl.

The mean monthly value of precipitation and evaporation from 1987 to 1993 and from 2000 to 2009 observed at Lebna dam office are shown in figure 2 . Mean annual precipitation is $432 \mathrm{~mm}$ so the area is classified as semi-arid. It has winter-wet and summer-dry seasons obviously, and in the summer-dry season, 

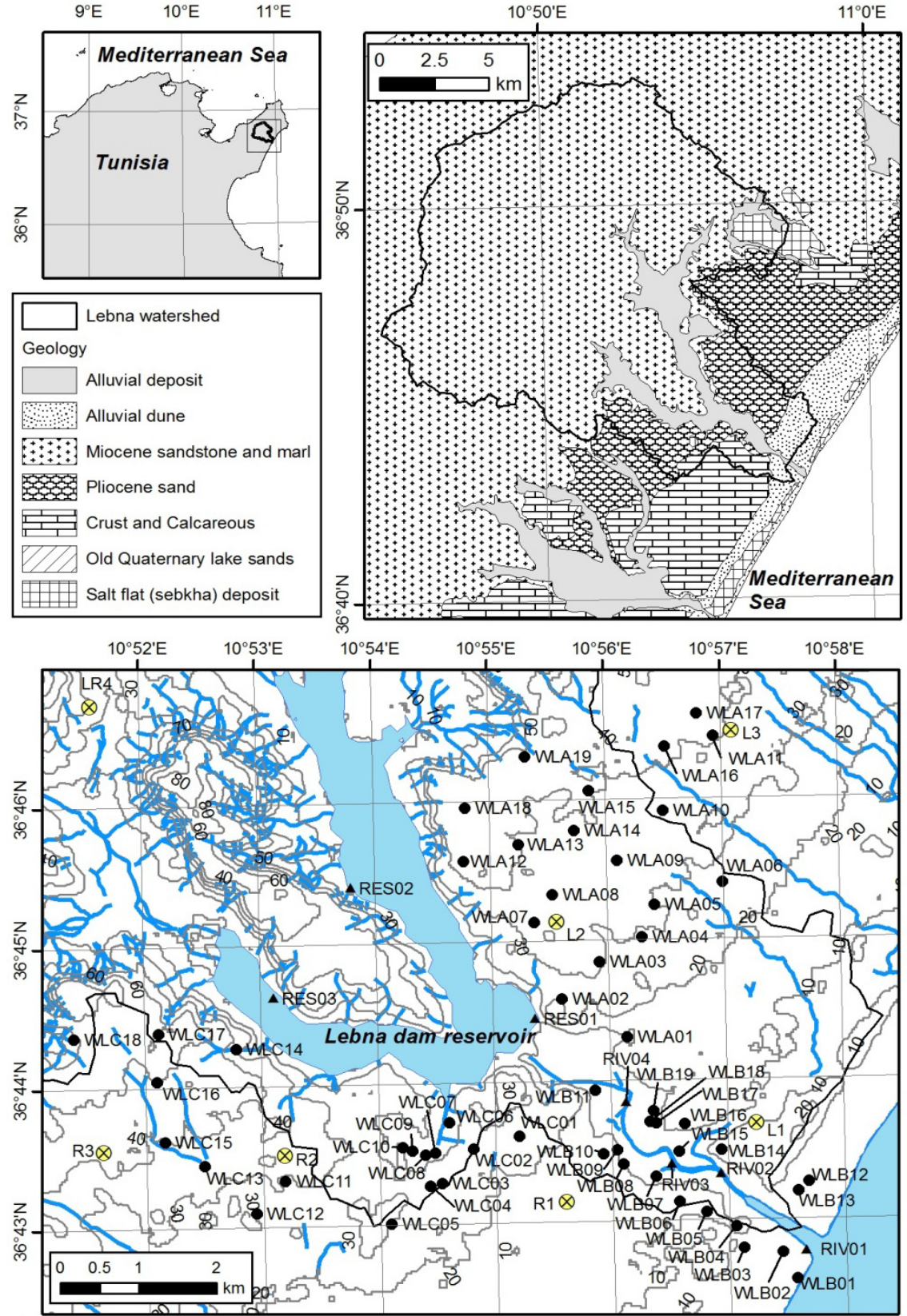

\begin{tabular}{|llll|}
\hline $\begin{array}{l}\text { Groundwater (historical data sets) } \\
\text { Water body(reservoir; sea) }\end{array}-$ Groundwater(private wells) & $\wedge$ & Surface water(reservoir; river) \\
\hline & & Hydronetwork & Contour line (10m interval) \\
\hline
\end{tabular}

Figure 1: Location of sampling site and geology map. 


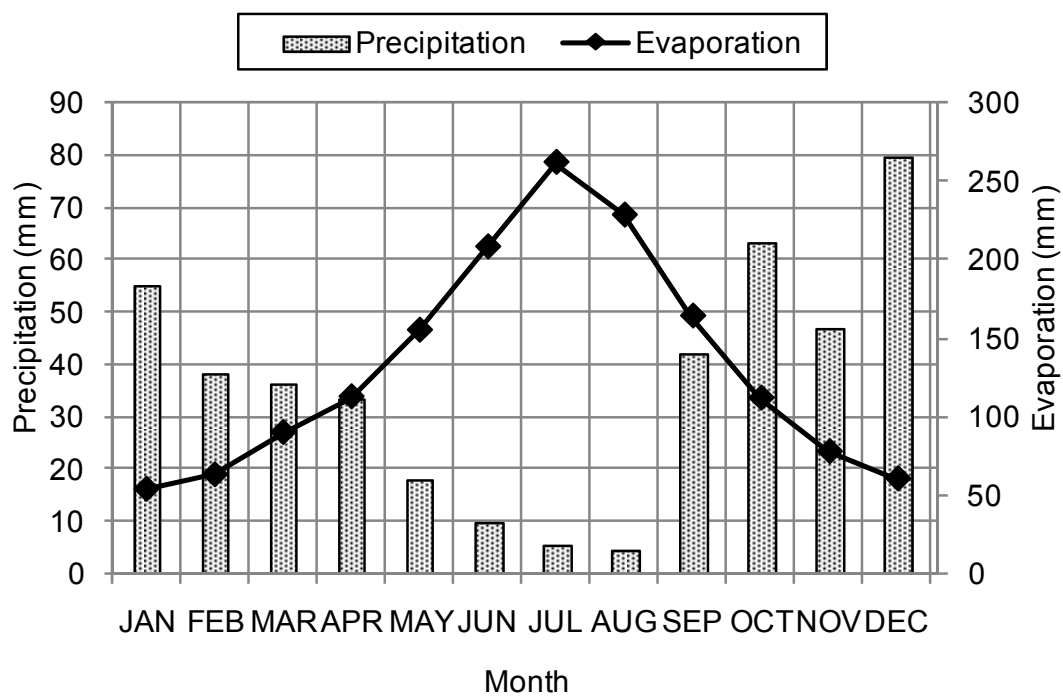

Figure 2: Monthly precipitation and evaporation. Mean values from 1987 to 1993 and from 2000 to 2009 observed at Lebna dam office.

water demand becomes so high due to irrigation that the rate of groundwater pumping gets larger than in the other period.

The Lebna dam constructed in 1986 is located approximately $4.5 \mathrm{~km}$ away from the coastal line. This reservoir is the largest reservoir in Cap Bon Peninsula. It was reported that reservoir water recharge to groundwater was 7.5 million $\mathrm{m}^{3} /$ year in 2004 estimated by a numerical simulation model [3]. However the spatial distribution of the reservoir effect has not been investigated yet.

Mean monthly water balance data of Lebna reservoir observed by CRDA (Commissariats Régionaux au Développement Agricole: Regional Commissary for Agricultural Development) is shown in figure 3.The data sets includes variation $(\Delta V)$ of water volume in the reservoir and water amounts of downstream river discharge $\left(Q_{D}\right)$, irrigation use $\left(Q_{I}\right)$ and evaporation $\left(Q_{E}\right)$ mainly, but does not include the inflow $\left(Q_{I N}\right)$ from the catchment area through the upstream river and precipitation $\left(Q_{P}\right)$. Thus, the contribution $\left(Q_{G W}\right)$ of groundwater recharge from the reservoir was estimated by the data sets as follows:

$$
\begin{gathered}
\Delta V=\left(Q_{I N}+Q_{P}\right)-\left(Q_{D}+Q_{I R}+Q_{E}+Q_{G W}\right) \\
Q_{G W}-\left(Q_{I N}+Q_{P}\right)=-\Delta V-\left(Q_{D}+Q_{I R}+Q_{E}\right)
\end{gathered}
$$

$Q_{I N}$ and $Q_{P}$ were unknown values, but in the summer dry season,

$$
Q_{I N}+Q_{P} \approx 0
$$


Thus,

$$
Q_{G W}=-\Delta V-\left(Q_{D}+Q_{I R}+Q_{E}\right)
$$

In figure 3, therefore, it is estimated that contribution for groundwater recharge is approximately 1 million $\mathrm{m}^{3}$ per month in summer season, and 12 million $\mathrm{m}^{3}$ per year simply.

\begin{tabular}{|ll|}
\hline Variation of water volume & $\square$ Discharge \\
Evaporation & $-\infty$ Irrigation \\
Contribution - Inflow & - WaterVolume \\
\hline
\end{tabular}

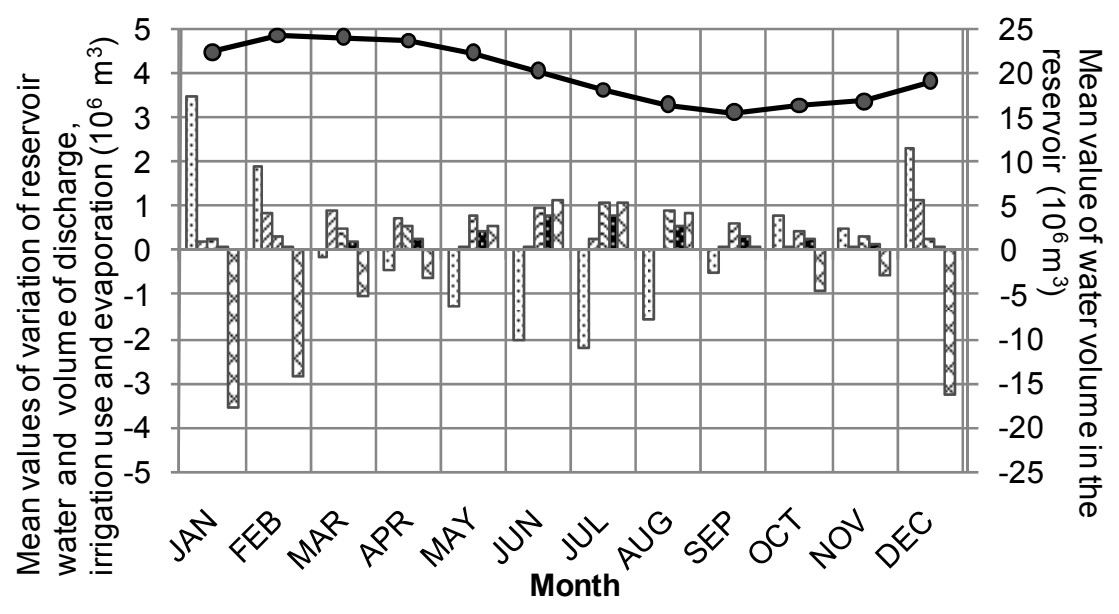

Figure 3: Monthly water balance data of Lebna reservoir observed by CRDA.

On the other hand, the historical groundwater table data and locations of 7 public and private wells (L1, 2, 3, R1, 2, 3 and LR4) are shown in figures 1 and 4. Generally there was no big change of water table before and after the dam construction except for R1. The water table of R1 has been changed gradually since 1996. It is not clear that the change is caused by the dam construction or not, but there is a possibility that the area affected by the infiltration from the reservoir water is limited.

In addition, the river mouth of the Lebna River seems to close. One of the reasons is the reduction of inflow from upstream after the dam construction. In previous research, seawater intrusion was not reported to occur around the mouth of the Lebna River. However, there is a possibility that high-salinity water remains in the mouth and infiltrates the shallow aquifer.

\section{Methodology}

In July 2010, groundwater table and spatial variations of chemical composition of ground and surface waters in the study area were investigated at a total of 63 

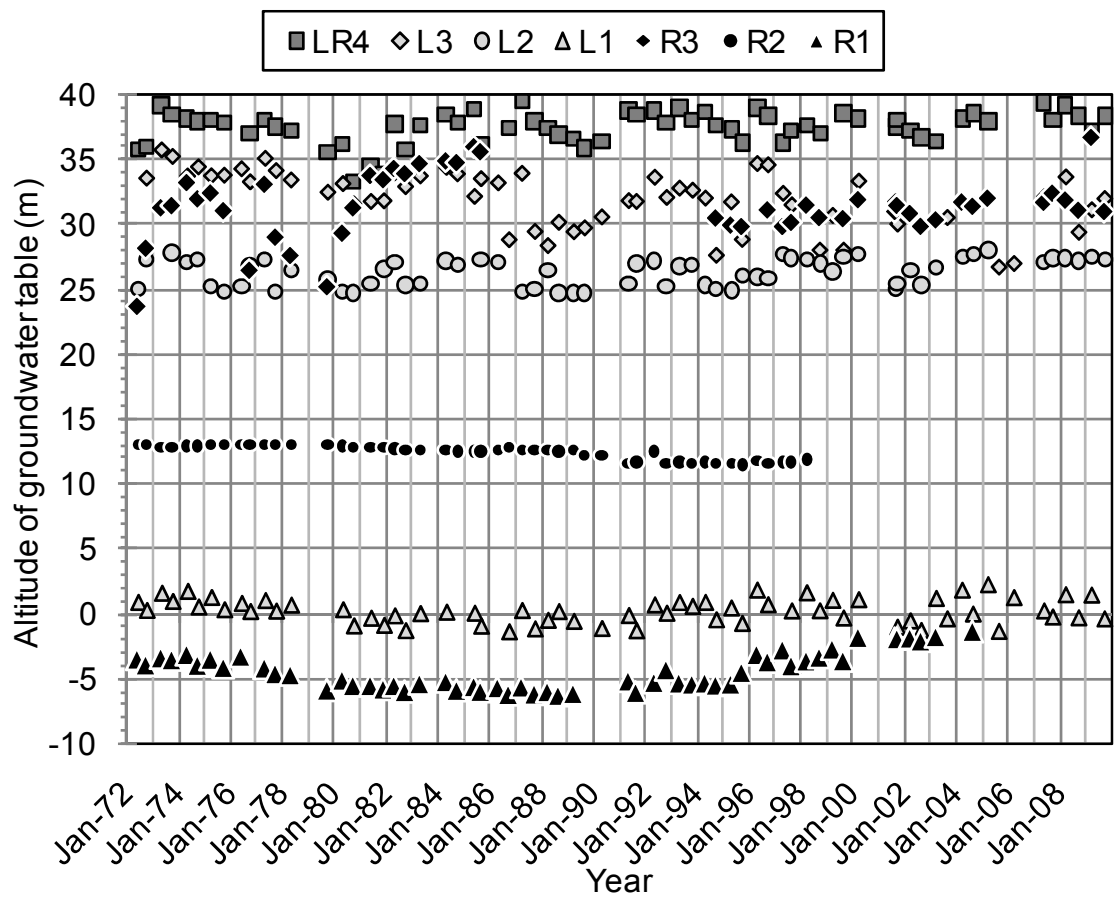

Figure 4: Historical data of the groundwater table measured at 7 public and private wells (L1, 2, 3, R1, 2, 3 and LR4) shown in figure 1.

locations as shown in figure 1: 56 groundwater samples from public and private wells in the areas named as WLA (19 locations in the left side of the Lebna dam reservoir), WLB (19 locations near the Lebna River in the downstream of the dam) and WLC (18 locations in the right side), and surface water samples from the reservoir (3 locations) and the downstream river (4 locations).

All the investigated locations were determined using a GPS devise (GARMIN Ltd., GPSMAP 76S). Groundwater level (YAMAYO MEASURING TOOLS CO., LTD., Million Water Level Measure), electrical conductivity(EC; YOKOGAWA Electric Co., SC82), pH and water temperature (YOKOGAWA Electric Co., pH81) were measured on site.

Then, in order to draw the groundwater table contour map, altitude of the ground level of all observed locations was calculated using inverse distance weighted (IDW) method with the data of the nearest three grid points of ASTER Global Digital Elevation Model whose spatial resolution is 30 meters. Contour lines of groundwater table were also plotted using IDW on ArcGIS.

On the other hand, each water sample was sealed in a 100-ml plastic bottle on site then brought back to a laboratory in Japan. Each sample was filtered through a cellulose acetate membrane $(0.20 \mu \mathrm{m})$ and diluted 10 to 250 times before analyses. Bicarbonates were calculated by the titration method (Metrohm, 645 Multi-Dosimat auto buret) and other anions $\left(\mathrm{Cl}^{-}, \mathrm{NO}_{3}{ }^{-}, \mathrm{SO}_{4}{ }^{2-}\right)$ were determined 
by Ion chromatography (IC; SHIMADZU, HIC-SP/VP super), and cations $\left(\mathrm{Na}^{+}\right.$, $\left.\mathrm{K}^{+}, \mathrm{Mg}^{2+}, \mathrm{Ca}^{2+}\right)$ and Silica $\left(\mathrm{SiO}_{2}\right)$ were determined by Inductive Coupled Plasma-Atomic Emission Spectroscopy (ICP-AES; Nippon Jarrell-Ash, ICAP757).

\section{Results and discussions}

\subsection{Groundwater contour map}

Figure 5 shows the groundwater table contour map. In general, the direction of groundwater flow in both sides of the reservoir was parallel to the reservoir. Thus, the interaction between the groundwater and reservoir water seemed to be so weak. The surface level of the reservoir water at RES01 was 16.25 meters, so the area where the groundwater level was lower than the surface level of the reservoir water was in the south part of the reservoir. Therefore, it was considered that the area affected by groundwater recharge from the reservoir water was limited there because of water head difference between surface water and groundwater.

On the other hand, the groundwater level from the river mouth to near the dam body was generally lower than sea level $(0 \mathrm{~m})$. Previous researches $[3,4]$

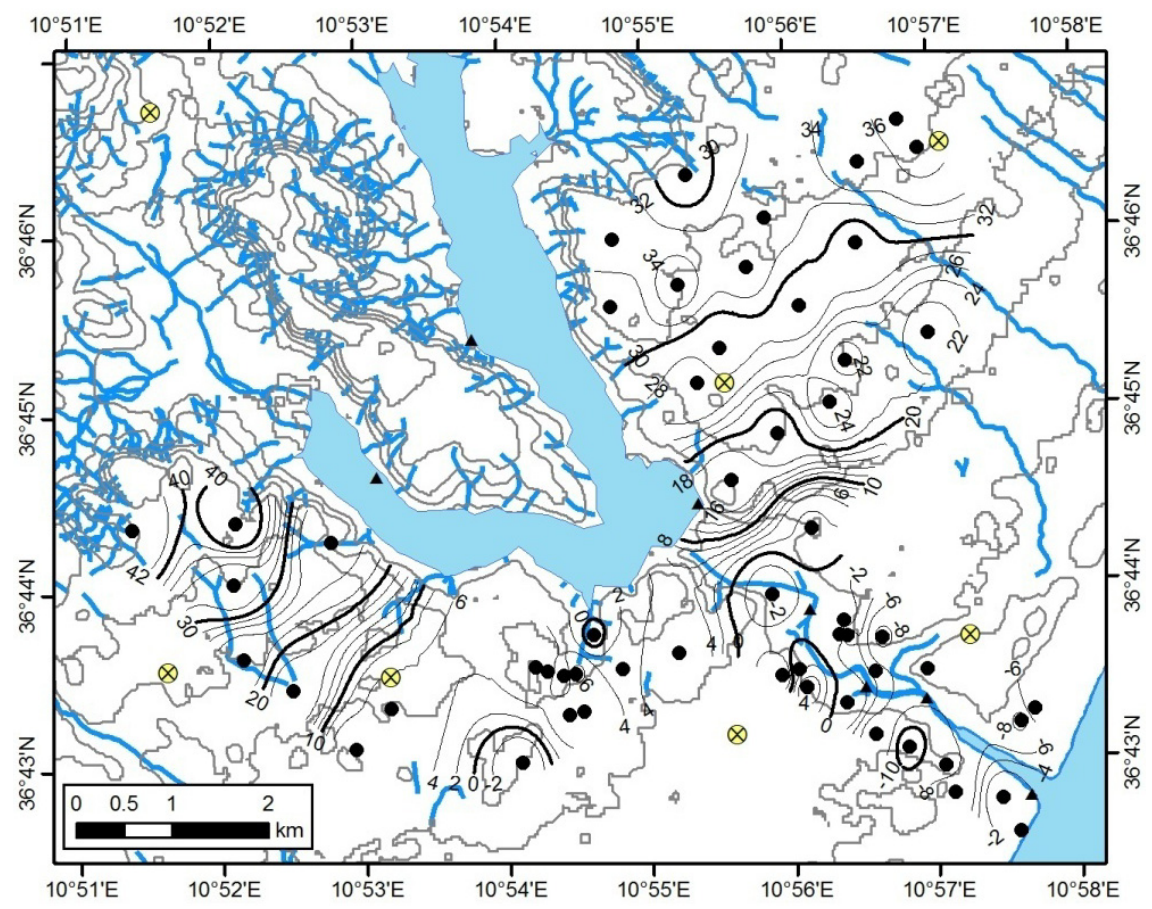

Figure 5: The groundwater table contour map measured in July 2010. 
have not reported that the groundwater level in the downstream area of the Lebna reservoir was lower than the sea level. Because the study area of those researches was larger than this study, the groundwater table has not been able to be determined in detail. Also, there was a chance of infiltration of river water, so the interaction of surface-groundwater was limited to the unidirectional water flow from surface water to groundwater, there was no water flow from the groundwater to surface water.

\subsection{Water quality}

Figure 6 shows the spatial distribution of EC, figure 7 shows the Piper's trilinear diagram, and figure 8 shows the spatial distribution of concentrations of major solute ions using hexadiagram (Stiff diagram).

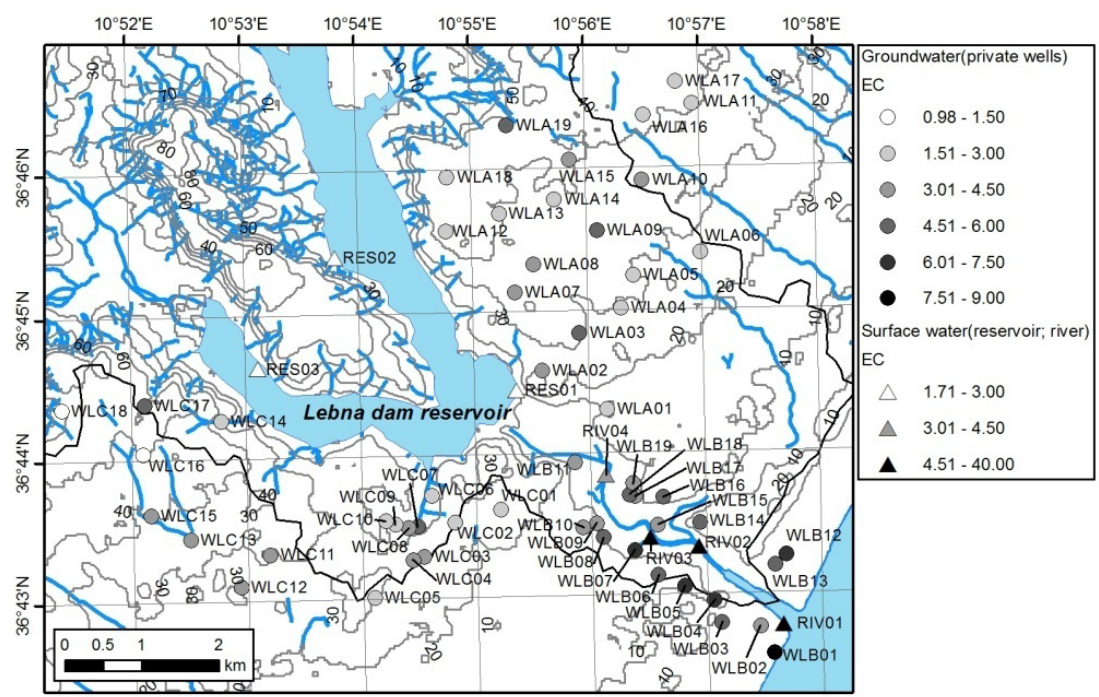

Figure 6: The spatial distribution of electric conductivity (EC).

First, the ECs of river water samples (RIV1 to 4)were so high and these sodium and chloride ions dominated in the chemical compositions ( $\mathrm{Na}-\mathrm{Cl}$ type), so the river waters except for RIV4 were the same as the quality of sea water. Reservoir water samples (RES1 to 3) was categorized as $\mathrm{Na}-\mathrm{Cl}$ type like river water samples, but the ECs were lower.

On the other hand, the salt contamination of groundwater was determined in not only the coastal side but also the hill side, according to the distribution of EC.4.5 to 9.0 of EC were observed in the WLB area which was the downstream of the reservoir. The water quality was categorized as not only $\mathrm{Na}-\mathrm{Cl}$ type like river water but also $\mathrm{Na}-\mathrm{Ca}-\mathrm{Cl}$ and $\mathrm{Ca}-\mathrm{Na}-\mathrm{Cl}$ types. These calcium ions were thought to originate at calcareous rock exiting in the right side of the Lebna River as shown in figure 1. 


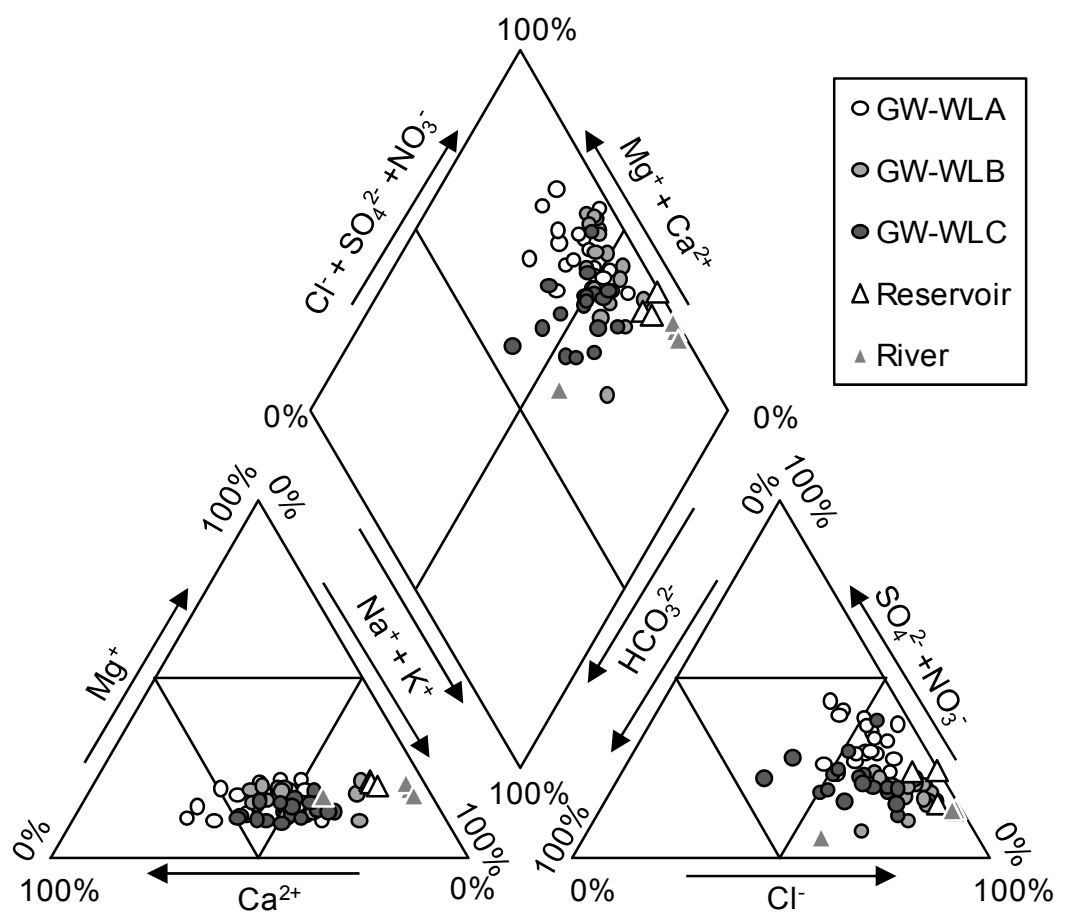

Figure 7: $\quad$ Piper's trilinear diagram.

As mentioned above, the groundwater level was lower than the sea level in that area. In addition, river water quality was the same as the sea water, thus, the contamination in that area had been caused by degradation of the groundwater level and the water quality of river water. The mouth of the Lebna River was closed due to sedimentation at the investigation, and the river flow stagnated. The sedimentation was thought to be caused by dam construction because the river flow has been stopped after the construction.

Also, in the hill side (WLA and WLC areas), 3.0 to 6.0 of EC were observed and the salt contamination was determined. According to the piper diagram (figure 7), the composition of anion was dominated by chloride, but the rate of sulfate and nitrate ions in a part of the samples was relatively higher. Thus, the spatial distribution of nitrate ion concentration is shown in figure 9. Nitrate, which is contained in fertilizer, is one of the water contaminants. It was contained in the groundwater samples; high concentration of nitrate was observed especially in the WLA area (WLA07 to 11, 15 to 17 and 19).

Next, the spatial distribution of chloride ion concentration is shown in figure 10 , to discuss the interaction between surface water and groundwater. Chloride is well-used as a tracer because of its conservativeness. The concentration of reservoir water was lower. So, chloride concentration of the groundwater samples located in the area contributed by the infiltration from the reservoir should become low. 


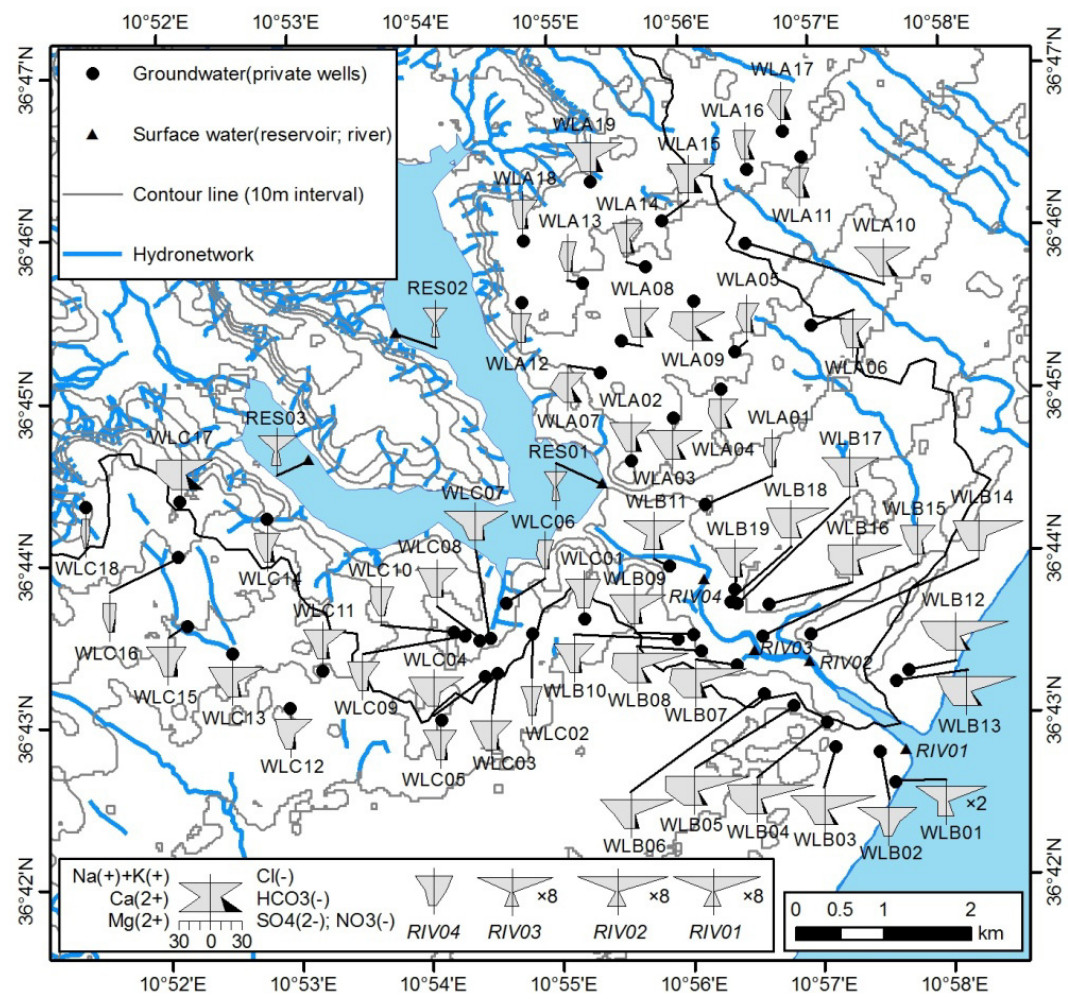

Figure 8: The spatial distribution of hexa (Stiff) diagram.

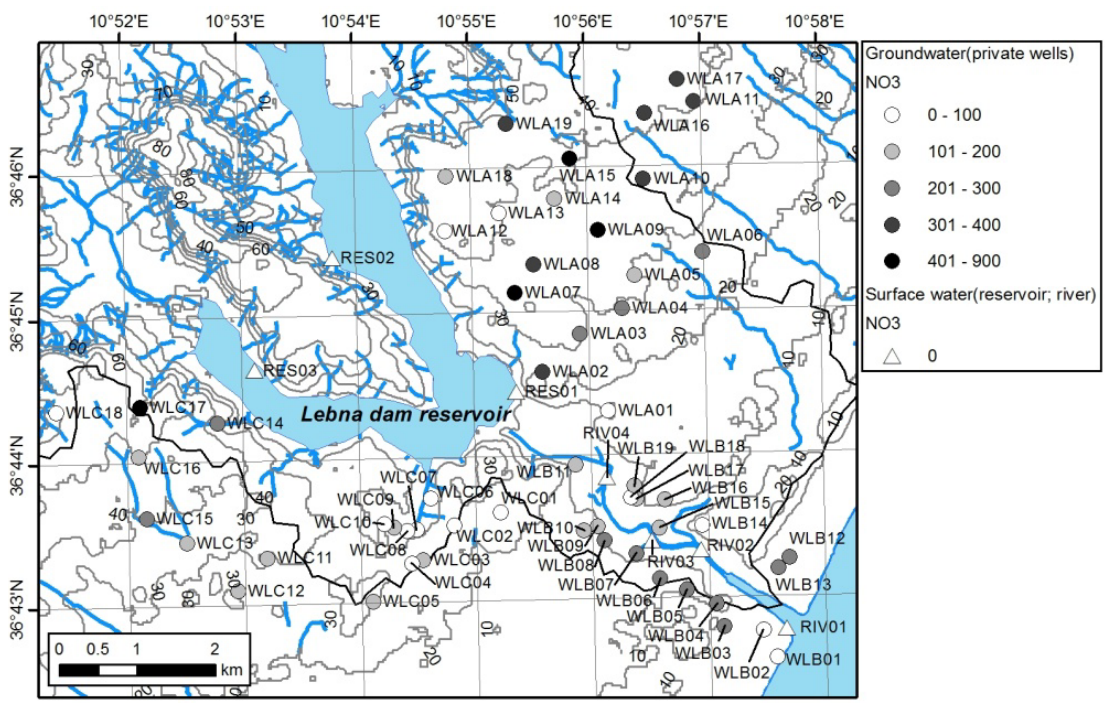

Figure 9: The spatial distribution of nitrate concentration. 


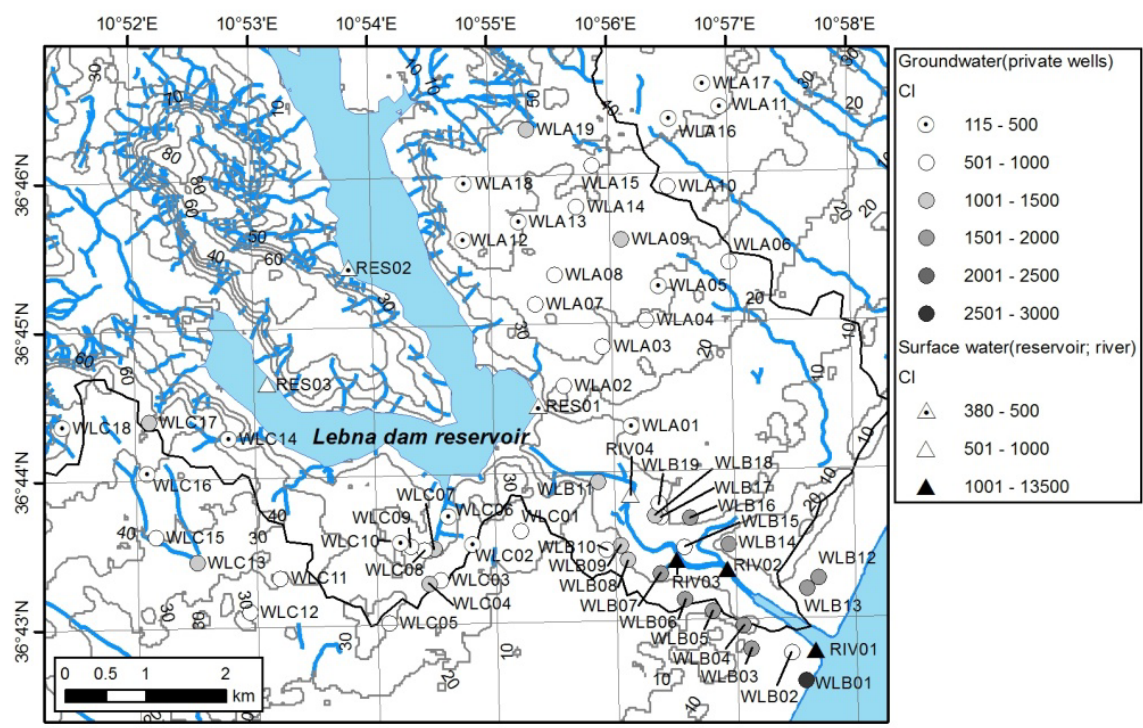

Figure 10: The spatial distribution of chloride concentration.

From this point of view, 4 areas were nominated as follows: area-1 (WLA12, 13 and 18), area-2 (WLA01), area-3 (WLC02, 06, and 10), and area-4 (WLC14, 16 and 18). The groundwater levels in area-2 and 3 were lower than the level of water surface of the reservoir as shown in figure 5, while the groundwater levels in area- 1 and 4 were higher. In figure 5, there was no the direction of water flow from the reservoir to area-2. However there is a possibility that the groundwater flow changes in the winter-rainy season. Therefore, it was considered that the reservoir water contributed to groundwater recharge in both area-2 and 3 .

\section{Conclusion}

The groundwater table and inorganic solute ions in groundwater and surface water were investigated around the Lebna reservoir and the downstream river in July 2010. As a result, seawater intrusion was determined around the estuary in detail, the river-mouth closure caused by the dam construction was thought to relate to the intensive seawater intrusion. Also, nitrate contamination of groundwater in the hill side was determined. The area affected by the infiltration of the reservoir water was limited to a part of the downstream area according to the spatial distribution of chloride concentration.

\section{Acknowledgements}

This research was supported by JST/JICA, SATREPS (Science and Technology Research Partnership for Sustainable Development) project (represented by Prof. Hiroko Isoda, University of Tsukuba), and Mitsui \& Co., Ltd. Environment Fund (2008-2010, represented by Prof. Hiroko Isoda). 


\section{References}

[1] Kouzana, L., Mammou, A. B. \& Felfoul, M. S., Seawater intrusion and associated processes: Case of the Korba aquifer (Cap-Bon, Tunisia), C. R. Geoscience, 341, pp. 21-35, 2009.

[2] Trabelsi, R., Zairi, M. \& Dhia H. B., Groundwater salinization of the Sfax superficial aquifer, Tunisia, Hydrogeology Journal, 15, pp. 1341-1355, 2007.

[3] Zghibi, A., Zouhri, L. \& Tarhouni, J., Groundwater modelling and marine intrusion in the semi-arid systems (Cap-Bon, Tunisia), Hydrological Processes, 25, pp. 1822-1836, 2011.

[4] Kerrou, J., Renard, P. \& Tarhouni, J., Status of the Korba groundwater resources (Tunisia): observations and three-dimensional modelling of seawater intrusion, Hydrogeology Journal, 18, pp. 1173-1190, 2010. 